\title{
EDUCAÇÃO INFANTIL: tensões presentes na esfera do trabalho docente
}

\author{
CHILDHOOD EDUCATION: tensions present in the teaching work sphere \\ EDUCACIÓN INFANTIL: las tensiones presentes en la esfera de la labor docente
}

\author{
Laís Leni Oliveira Lima \\ Professora Doutora pela Faculdade de Educação da Universidade Federal de Goiás \\ laisleni@gmail.com \\ Cátia Regina Assis Almeida Leal \\ Professora Doutora pela Faculdade de Educação da Universidade Federal de Goiás. \\ catiaassisleal@gmail.com
}

\begin{abstract}
RESUMO: O artigo apresenta resultados de uma pesquisa, cujos objetivos, entre outros, foram compreender as tensões encontradas nos desdobramentos do trabalho que se realiza na Educação Infantil (EI), e as consequentes perdas de prestígio social na carreira do professor, interferindo na constituição de sua identidade política. Para isso, foram buscadas proposições teóricas que fundamentam a categoria trabalho como atividade ontológica do ser humano e as ações que afetam o mundo do trabalho e a constituição de organização política da classe trabalhadora ${ }^{1}$, em específico do trabalho docente na El. A abordagem teórica esteve alicerçada na perspectiva do materialismo histórico dialético e as metodologias utilizadas foram as necessárias para o desvelamento do objeto de estudo. Foram pesquisadas 44 trabalhadoras da El, em sete instituições localizadas nos municípios de Jataí, Serranópolis e Chapadão do Céu - localizados na microrregião do Sudoeste do Estado de Goiás. A pesquisa evidencia que a concepção fetichizada da existência das crianças pequenas, interfere no trabalho realizado pelas trabalhadoras, $\mathrm{e}$ isso não tem contribuído para a consolidação de ações educativas ancorado no domínio da ciência nessas instituições. A pesquisa revela a necessidade e a possibilidade da trabalhadora, que atua na El, se assumir como trabalhadora docente, o que requer conhecimentos profundos e sólidos a respeito da especificidade do desenvolvimento do trabalho formativo.
\end{abstract}

PALAVRAS-CHAVE: Trabalho. Trabalho docente. Educação infantil.

ABSTRACT: The article presents results of a survey whose goals, among others, was to understand the tensions found in work developed in Early Childhood Education and the consequent loss of social prestige in the teacher's career, interfering in his political identity formation. For this, it sought theoretical propositions to base the job while category as human ontological activity and actions that affect the world of work and the constitution of the political organization of the working class, in particular the teaching work in CE. The theoretical approach was grounded in the perspective of dialectical historical materialism and the methodologies used were necessary for the unveiling of the subject of study. The search was realized with 44 workers of CE in seven institutions located in the municipalities of Jataí, Serranópolis and Chapadão do Céu - Located in the Southwest micro region of the State of Goiás. The Research shows that fetishistic conception of the existence of small children, interferes in the work done by those workers, and this has not contributed to the consolidation of educational activities anchored in science domain in these institutions. The survey reveals the need and the possibility of worker, engaged in CE, assuming herself as a teaching worker, which requires extensive and solid knowledge about the specificity of the development of formative work.

KEYWORDS: Work. Teaching work. Childhood education.

\footnotetext{
${ }^{1}$ Durante a pesquisa não foi encontrado nenhum profissional do sexo masculino, houve predominância de mulheres em todos os segmentos pesquisados. Por isso, usar-se-á em todo texto a flexão no feminino.
}

Artigo recebido em janeiro de 2016

Aprovado em março de 2016 
RESUMEN: El artículo presenta resultados de una investigación, cuyos objetivos, entre otros, fue entender las tensiones en el desarrollo de la labor que ocurre en educación infantil (EI) y la consiguiente pérdida de prestigio social en la carrera del profesor, interfiriendo en la formación de su identidad política. Para ello, se buscó las proposiciones teóricas que fundamentan la categoría trabajo como actividad humana ontológica y las acciones que afectan el mundo del trabajo y el establecimiento de la organización política de la clase obrera, en específico la labor docente en El. El enfoque teórico se basó en la perspectiva del materialismo histórico dialéctico y las metodologías utilizadas fueron necesarias para la presentación del objeto de estudio. Fueron investigadas 44 trabajadoras de la El en siete instituciones ubicadas en los municipios de Jataí, Serranópolis y Chapadão do Céu - situados en la región del suroeste de la provincia de Goiás, Brasil. La investigación muestra que la concepción fetichizada de la existencia de niños y niñas interfiere con el trabajo realizado por las trabajadoras, y esto no ha contribuido a la consolidación de acciones educativas relacionada al dominio de la ciencia en estas instituciones. El estudio revela la necesidad y la posibilidad de la trabajadora que actúa en la El, adjudicarse como trabajadora docente, lo que requiere conocimientos profundos y sólidos sobre la especificidad del desarrollo del trabajo formativo.

PALABRAS CLAVE: Trabajo. Labor del docente. Educación infantil. 


\section{1| INTRODUÇÃO}

Abordagens teóricas, no final do século XX e início do século XXI, sobre o reconhecimento da existência da especificidade no trabalho pedagógico com crianças menores de cinco anos ${ }^{2}$ e os esforços dos movimentos da sociedade civil para a defesa do caráter "educativo" da Educação Infantil (EI), contribuíram para o reconhecimento dos profissionais nela inseridos como docentes tanto para a formação de educadores infantis, quanto para a inclusão dessa etapa de educação nos sistemas de ensino.

A partir da década de 1990, os trabalhadores que atuavam nas instituições de El começaram a ganhar "destaque". Surgiram diferentes produções - Kishimoto (1999), Rosemberg (2002), Kramer (2003), Kuhlmann Junior (1998, 1999), Kuhlmann Junior e Fernandes (2004), - que debatem sobre esses educadores, suas funções e formações. Esses estudos procuravam mostrar quem eram os profissionais que atuavam nas instituições realizando o trabalho de cuidar e de educar crianças menores de cinco anos e de como esse trabalho era organizado.

Um aspecto significativo, nessa trajetória da educação de crianças menores de 5 anos é a pressão de movimentos sociais organizados pela ampliação e qualificação desse atendimento. Historicamente, essa demanda aumenta na medida em que cresce a inserção da mulher no mercado de trabalho, no entanto, contemporaneamente, esse crescimento vem acompanhado da luta por uma educação com o máximo de sistematização possível.

Pesquisas como as de Arce (2001), Martins e Arce (2007), Stemmer (2007, 2012), Prado e Azevedo (2012), Saviani, N. (2012), Alvarenga (2012), dentre outras, corroboram com isso, quando indicam que o pleno desenvolvimento e humanização das crianças prevê finalidades, precisão, rigor teórico, disciplina metodológica, na forma de entender e trabalhar o conhecimento no contexto em que foi produzido. Como afirma Lukács (1979) requer a efetivação do pôr teleológico dessas trabalhadoras por meio do conhecimento de causas que possibilitam à trabalhadora a compreensão do ponto de partida e do ponto de chegada.

No entanto, Campos e Cruz (2006) indicam como resultados de suas pesquisas, que a valorização da profissional para a El ainda não se materializou. Nesse contexto, entende-se também, ser de fundamental importância compreender as diferentes transformações ocorridas com as trabalhadoras da El, e como essas mudanças interferiram e interferem na constituição dos desdobramentos dos trabalhos realizados por elas nessas instituições.

Este texto objetiva compreender as tensões encontradas nos desdobramentos do trabalho que se realiza na El. Apresenta-se subdivido em quatro seções: a primeira apresenta a relação entre trabalho e educação e a especificidade do trabalho em Educação Infantil; a segunda, aborda o método de exposição e pesquisa; a terceira debate as tensões presentes no trabalho na Educação Infantil; e, por fim, a quarta trata da necessidade da (des)naturalização do processo de aprendizagem na El e o papel da professora nela inserida.

\footnotetext{
${ }^{2}$ Conforme a Lei $n^{\circ} 11.274$, aprovada em fevereiro de 2006, modificou-se a educação básica ao estender o Ensino Fundamental para nove (9) anos. Essa legislação altera a entrada da criança no Ensino Fundamental que passa a acontecer aos seis (6) anos de idade, reduzindo a população a ser atendida nas instituições de Educação Infantil para até os 5 anos de idade. Outra recente Resolução do Conselho Municipal de Educação de Jataí-Go (um dos locais da pesquisa), n 023/07, Art. $6^{\circ}$ afirma que: "os alunos deverão ser matriculados no Ensino Fundamental de 09 anos com idade mínima de 06 (seis) anos ou a completar até 31 de janeiro do ano letivo em curso"; por isso, ao longo deste texto faremos referência ao atendimento às crianças em instituições de El com idade entre 0 e 05 anos.
} 


\section{2 | TRABALHO E EDUCAÇÃO: a especificidade do trabalho em Educação Infantil}

Parte-se do princípio de que o trabalho é fundante na essência humana. Como afirma Lukács (1979, p. 4) "somente o trabalho tem, como sua essência ontológica, um claro caráter intermediário: ele é essencialmente, uma interação entre homem (sociedade) e natureza". Já Marx (1983) afirma que ontologicamente o trabalho é uma atividade inerente ao homem, pois este expressa seu caráter genérico enquanto trabalhador, na produção e reprodução de suas condições materiais. À medida que o homem se destaca na natureza, ele se constitui como homem e ser social. Por meio do trabalho o homem se apropria da natureza, transformando-a e imprimindo nela suas características. Essas características acumulam-se com o passar das gerações, criando necessidades para as novas gerações se apropriarem dos produtos culturais produzidos pela atividade humana. Esse processo se constitui como prática educativa, uma vez que, para ocorrer, necessita do conhecimento e da experiência transmitida por outros indivíduos, especialmente os adultos. Diante desta afirmação compreende-se que a educação também é inerente ao ser humano, pois, originou-se do mesmo processo que deu origem social ao homem. Assim "desde que o homem é homem ele vive em sociedade e se desenvolve pela mediação da educação" (SAVIANI, D., 1994, p.1).

Nesse sentido, a problemática referente à relação entre trabalho e educação pode ser articulada com a questão da natureza do trabalho em educação. Entretanto, é preciso pensar, antes de prosseguir a análise, o que significa a expressão "trabalhadores em educação" e quem é o trabalhador em Educação Infantil (El).

Trabalhadores em educação seriam os profissionais que se dedicam à atividade de "ensinar" intencionalmente. Segundo Luckesi (1995), é aquele que cria condições de desenvolvimento de condutas desejáveis, seja do ponto de vista do indivíduo, seja do ponto de vista do grupo humano. São os que passam por um processo formal de aquisição de conhecimentos e habilidades, garantidos por uma instituição de nível superior ou não, preparados para atuar no magistério ou em outras atividades. Vence-se, assim, no decorrer de alguns anos, currículos e programas, tendo em vista a habilitação para atuar na El ou nos demais níveis e modalidades de ensino.

Faz-se necessário também recorrer à noção histórica das transformações ocorridas na construção do trabalho docente, visto que este, a organização escolar e, em especial o trabalho do profissional da educação, no processo de consolidação e constituição da sociedade, têm se submetido às variadas formas de estrutura organizacional, uma vez que, a própria historicidade deste trabalho, constitui uma expressão e uma resposta à sociedade na qual está inserida. Essas formas de organização são expressões materiais do desenvolvimento social, econômico e cultural da sociedade, que impuseram uma constituição no ser e no agir da trabalhadora da educação. Essas dimensões se entrecruzam nas relações sociais e no interior das instituições escolares e não há como compreender esse trabalho somente por um aspecto, mas nas relações entre ambos. Por isso, nunca neutro, mas comprometido ideológica e politicamente.

Essas formas de organização são expressões materiais do desenvolvimento social, econômico e cultural da sociedade, que impuseram uma constituição no ser e no agir dos trabalhadores da educação. Tais dimensões organizativas se entrecruzam nas relações sociais e no interior das instituições escolares e não há como compreender esse trabalho somente por um aspecto, mas nas relações entre ele e a educação.

Concebe-se o trabalhador docente, antes de tudo, como um ser humano, e, como tal, sujeito da história, visto que é o trabalho que empresta ao homem sua característica histórica. Segundo Paro (2000, p. 29-30, grifo do autor), 


\begin{abstract}
O meramente natural não tem história. Quando consideramos uma espécie animal, por exemplo, no período de cem anos, constatamos não ter havido mudanças. O animal é o mesmo no decorrer do tempo porque está preso a sua necessidade (ou "necessariedade") natural. Isso porque conceituamos o animal em sua finitude natural. Com o homem a coisa é diferente. [...] O homem é sua "porção" natural e aquilo que ele produz. E aquilo que ele produz modifica permanentemente seu meio. [...] Essa transcendência do meramente natural que o faz um ser histórico o homem consegue pelo trabalho.
\end{abstract}

Entende-se que o trabalhador em educação tem um papel fundamental no desenvolvimento e execução de um projeto histórico que esteja voltado para o homem, como protagonista de um projeto histórico de desenvolvimento do povo, do qual é parte intrínseca. É como outros profissionais, construtor da história, na medida em que age conscientemente. O trabalhador em educação é visto como um sujeito que, conjuntamente com outros sujeitos, constrói seu agir, seu projeto histórico de desenvolvimento do povo, que se traduz e se executa em um projeto pedagógico. Assim sendo, ele não poderá exercer as suas atividades isento de opções teóricas e políticas, ou porque tem afeto pelas crianças.

Saviani, D. (1991) e Paro (2000) ressaltam que, para discutir a natureza do trabalho dos professores é preciso contemplar os conceitos marxianos de produção material e não material ${ }^{3}$, pois, somente assim, segundo os autores, é possível avançar e superar a polêmica povoada entre trabalho produtivo e não produtivo. Segundo Paro (2000), a natureza do trabalho pedagógico é não material. Seu produto não é um objeto "material", mas um serviço.

Falar da natureza do trabalho docente na El, de certa forma é novidade, visto que as bases didáticas dessa etapa de educação no Brasil se deram calcadas na herança de uma psicologia do desenvolvimento de duas maneiras: uma, pautada na padronização de práticas homogeneizadoras, com as mesmas intenções das escolares; outra, alicerçada na construção de uma "pedagogia da infância”, baseada em métodos filosóficos, pedagógicos, com a crença de que o papel do adulto na aprendizagem da criança é apenas de facilitador, orientador, estimulador; relação na qual o conhecimento é sempre negociável.

Quando transpõe-se o conceito marxiano de trabalho para o trabalho pedagógico na El, determinadas especificações precisam ser feitas em relação à natureza do trabalho na El. Em primeiro lugar, a El não tem os mesmos moldes da educação escolar, entretanto, não se pode desvinculá-la da escolar. Porém, esse discurso tem polarizado muitas produções teóricas nessa área. Como assegura Arce (2004), estes fazem esforço para contrapor uma "cultura da infância" à educação escolar tradicional. Na sequência esta autora afirma:

Tem se aí um campo de batalha nitidamente demarcado: de um lado, entrincheirada, encontra-se a "pedagogia antiescolar" da educação infantil; do outro lado a pedagogia escolar do ensino básico e média que, por sua vez, é alvo constante do assédio sedutor das idéias construtivistas e pós-modernas, além de ser vítima da deteriorização das condições objetivas do trabalho docente produzidos pelas políticas educacionais neoliberais. (ARCE, 2004, p. 158).

A partir das reflexões de Arce (2004), questiona-se: é possível cortar definitivamente todos os laços da El com o ensino e com a figura do professor que transmite conhecimento às crianças? É possível haver educação sem ensino? O que diferenciaria então uma instituição de El perante outras instituições, como um clube, um parque, onde a criança também brinca e interage?

${ }^{3}$ Para maiores informações ver Paro (2000). 
Entende-se que é mediante o ensino que as instituições de El se caracterizam e se diferenciam das demais. Negar o ensino é negar o princípio educativo básico que é a humanização da criança, é dificultar que ela cresça e se transforme em um ser humano adulto, livre e consciente.

Considera-se que a educação não se reduz ao ensino, porém, como afirma Saviani, D. (2003, p. 14), o ensino é um aspecto da educação e participa da natureza própria do fenômeno educativo, "a própria institucionalização do pedagógico por meio da escola é um indício da especificidade da educação, uma vez que, se a educação não fosse dotada de identidade própria, seria impossível sua institucionalização".

Corroborando com essa posição, postula-se que a instituição de El se configura como instituição escolar de significativa qualidade educativa para as crianças de camadas populares, num espaço privilegiado para a dimensão pedagógica, por isso, defende-se que, ser educador na instituição de El não é ser espontaneísta, porque as instituições não trabalham com conteúdos escolares e o educador não ministra disciplinas, justificando ausência de planejamento, devido à crença de que é a criança quem dita o ritmo do trabalho e o educador apenas segue, ou de que o conhecimento proveniente da prática do cotidiano das crianças e educadores vale mais do que qualquer teoria. Também não é pensar que somente o lúdico e o prazeroso é que deve ser o eixo da prática educativa "a brincadeira passa a ser o escudo contra a falta de prazer que traz a escolarização e um antídoto assassinato da espontaneidade também causado por esta. [...] o lúdico passa a figurar como sinônimo de prazer" (ARCE, 2004, p. 159). Acredita-se que a brincadeira é importante na formação da criança, porém, esta não pode ser reduzida a um processo de naturalização, visto que, se a brincadeira se situar somente no âmbito do prazer, ela se desconstitui de seu significado social e histórico.

É verdade que determinadas pessoas manifestam especial tendência e gosto por crianças maiores ou menores, uns gostam mais, outros gostam menos do magistério. O que conta nessas instituições não é a técnica ou o "dom”. Segundo Arce (2004, p. 160),

Nessa pedagogia da infância, centrada nas relações e nas múltiplas linguagens, transfor-
mando-se assim numa pedagogia das diferenças, das relações, da escuta e da animação,
o professor sofre um violento processo de descaracterização, deixando de ensinar e re-
duzindo sua interferência na sala de aula a uma mera participação. O próprio uso da pala-
vra 'professor' chega a ser colocado em questão na área, não havendo consenso quanto
a adequação ou não desse termo, posto que ele carrega resquícios da idéia de educação
escolar e de alguém que ensina.

Nesse sentido, faz-se necessário o domínio das bases teórico-científicas e técnicas, e sua articulação concreta com as exigências educacionais de uma instituição de El. Essas questões permitem maior segurança ao trabalhador, de modo que o docente adquira base para pensar sua prática, aprimorar sempre mais a qualidade de seu trabalho e compreender a natureza do trabalho desenvolvido.

Uma questão que chama a atenção na natureza do trabalho na El é o fato de que, apesar da forma societal exigir um trabalhador com diferentes "habilidades", ou seja, que domine todo processo de trabalho - planejamento, execução - essa exigência remete a uma reflexão sobre o aspecto social da dualidade do trabalho, ainda muito presente nas instituições de EI - funções intelectuais / pedagógicas ou funções instrumentais.

O processo de consolidação da sociedade capitalista, busca evidenciar que "separou as mãos do cérebro", mas que esta é uma falsa separação. Entretanto, esse processo subsiste nas práticas cotidianas, especialmente nas instituições de $\mathrm{El}$ - as quais ainda reforçam que as atividades realizadas no interior das instituições, que não têm a "forma escolar" são menores, isto é, são menos valorizadas, porque estão relacionados ao domínio da prática, do trabalho não material. 
$\mathrm{Na}$ verdade, essa separação entre quem cuida e quem educa evidencia que o trabalho pedagógico desenvolvido em uma instituições de El se encontra subordinado à lógica do modo de produção capitalista. Segundo Freitas (1995), as mãos só estão separadas do cérebro na ossatura dessa sociedade da morte, que é a sociedade salarial, sendo esta é uma separação inconsistente e irreal.

Ao analisar o processo histórico ${ }^{4}$, de constituição das instituições de El, verifica-se que as mesmas surgiram acompanhando a estruturação do capitalismo, a crescente urbanização e a necessidade que o capital teve da reprodução da força de trabalho, com destaque para a força de trabalho das mulheres para produzir mais "capital", o que fez com que essas precisassem de um lugar para deixar os filhos. Além disso, havia a necessidade de força de trabalho - futuro - composta por seres capazes, nutridos, higiênicos e dóceis. A creche, como foi instituída configurou-se num lócus privilegiado para "fabricação" dessa vindoura força de trabalho.

Nesse sentido, a creche surgiu também com objetivo de legitimar o capital. Como afirma Mészàros (2002), a educação subsumida ao capital serve como processo de interiorização de preceitos, valores e condições de legitimidade do sistema. Dessa forma, a El contribui com o processo de reprodução das relações sociais de reprodução do sóciometabolismo do capital por meio da colaboração na reprodução da mercadoria força de trabalho, pela liberação da mão de obra feminina para o trabalho produtivo e pela inculcação ideológica de valores, princípios e relações das classes dominantes na criança da classe trabalhadora.

Do exposto, conclui-se que o sistema econômico vigente apropria-se inteiramente da organização da instituição e do saber, desqualificando o trabalhador, principalmente da El, justificando que basta gostar de crianças para ali trabalhar. Embora não de modo aparente, esta instituição já se encontra sob o domínio do capital e o processo de trabalho passa também a se subordinar ao capital.

As tensões geradas nesse processo resvalam na realidade vivida, no dia a dia do trabalho das profissionais da $\mathrm{El}$, e, certamente influi na maneira como concebem a infância, a criança, a função da El e, consequentemente, na construção de sua identidade política.

\section{3 | O MÉTODO EM QUESTÃO}

Esse artigo apresenta resultados de uma pesquisa, cujo um dos objetivos foi compreender as tensões encontradas nos desdobramentos do trabalho que se realiza na Educação Infantil (El). Essa apreensão possibilitou evidenciar o histórico das instituições pesquisadas e sua particularidade social: aspectos históricos, ideológicos, políticos físicos, organizacionais, culturais e socioeconômicos.

Procurou-se, durante as análises, apreender a particularidade histórica, sem perder de vista sua universalidade, isto é, ao mesmo tempo em que as características das instituições e a concepção das trabalhadoras da El nos municípios pesquisados aparecem como uma realidade diferente das de outros municípios, na verdade, essa diferença foi percebida como a representação de seu grau de universalidade.

Trata-se de um movimento com o pensamento científico, no sentido de apanhar as mediações e procurar a essência daquilo que não está dado em sua aparência, e, nesse caso, construir uma totalidade, rompendo com o nível de representação e elaborando conceitos que são sínteses das mediações apresentadas.

\footnotetext{
${ }^{4}$ Estudos detalhado sobre esse assunto é feito por vários autores, dentre eles: Merisse (1997); Haddad (1993).
} 
Acredita-se que este objeto de estudo é algo vivo e está em constante movimento. Dessa forma, faz-se necessários diferentes recursos metodológicos para sua apreensão e compreensão. A abordagem metodológica utilizada no decorrer da pesquisa foi de caráter exploratório com procedimentos predominantemente qualitativos, entretanto, sem abandonar elementos quantitativos.

Nessa perspectiva pressupôs-se a construção de uma totalidade significativa, com pretensão de ser aberta, transitória e histórica; ela não pode ser vista apenas como soma das partes ou como conjunto de dados empíricos sobre o objeto, mas afirmado como "síntese de muitas determinações" que nele a pesquisa permite revelar.

A caracterização geral das instituições auxiliou a situar os diversos locais nos quais se desenvolveu a pesquisa. Fez-se um levantamento quantitativo de todas as instituições dos municípios pesquisados, o número de profissionais (diretores, coordenadores, professores, monitores, agente social de serviço) e do nível de formação daqueles que trabalham diretamente com as crianças.

A partir destes levantamentos iniciais, visitou-se todos os Centros Municipais de Educação Infantil (Cmei) para registrar as características gerais dessa etapa de educação e conhecer o perfil das trabalhadoras ali inseridas. Todas as instituições são classificadas como Cmei, visto que estas atendem crianças de 4 (quatro) meses a 5 (cinco) anos. Essa caracterização é importante em razão da heterogeneidade existente entre os estabelecimentos que oferecem El e da visualização da realidade vivida pelas pessoas entrevistadas.

A pesquisa foi realizada em sete Centros Municipais de Educação Infantil (Cmei), sendo cinco no município de Jataí, um no município de Serranópolis e um no município de Chapadão do Céu - localizados na microrregião do Sudoeste do Estado de Goiás.

Numa primeira etapa, os dados da pesquisa permitiu caracterizar as trabalhadoras das instituições públicas de El dos municípios pesquisados por meio de um questionário fechado, observando as variáveis idade, sexo, estado civil, número de filhos, formação, tempo de trabalho na instituição.

Numa segunda etapa, após a caracterização, formou-se três grupos, compostos por: professoras, agentes educativas e diretoras e ou coordenadoras. Os grupos foram homogêneos em sua singularidade, enquanto expressão da heterogeneidade do conjunto estudado. Essa etapa investigativa permitiu conhecer as concepções de criança, infância, educação infantil, características de um trabalhador para atuar na El, dentre outros aspectos, dessa forma, procurou-se, em seguida, apreender o movimento de fetichismo da infância e sua influência nas tensões do trabalho que se estrutura e se realiza nas instituições de El.

Para isso, utilizou-se outros instrumentos metodológicos, tais como entrevistas e observações com as trabalhadoras das instituições dos municípios pesquisados. O número de trabalhadoras pesquisadas - diretoras, coordenadoras pedagógicas, professoras e agentes-educativas - foram 44. A escolha dependeu da organização do trabalho e horário de cada instituição pesquisada.

Tabela 1 - Trabalhadoras pesquisadas por município.

\begin{tabular}{|c|c|c|c|c|}
\hline Local & Agentes educativos & Coord./diretoras & Professoras & Total \\
\hline Jataí & 13 & 8 & 12 & 33 \\
\hline Serranópolis & 1 & 2 & 3 & 6 \\
\hline Chapadão do Céu & 1 & 2 & 2 & 5 \\
\hline \multicolumn{4}{|c|}{ Total } & 44 \\
\hline
\end{tabular}

Fonte: Dados da pesquisa. 
EDUCAÇÃO INFANTIL | Laís Leni O. Lima e Cátia Regina A. Almeida Leal

Todos esses instrumentos metodológicos foram utilizados respeitando os rigores éticos de pesquisa com seres humanos e com o objetivo de desvelar o objeto de pesquisa em sua essência (LAKATOS; MARCONI, 1986; FAZENDA, 1989; FRIGOTTO, 1989; SANTOS FILHO; GAMBOA, 2001).

Essa fase da pesquisa procurou dar "voz" às trabalhadoras, para que elas falassem sobre suas concepções de infância, de criança, de educação, de ser professoras na El, de avaliarem suas condições de trabalho, incluindo salário, infraestrutura e material disponível, dentre outros.

\section{4 | TRABALHO NA EDUCAÇÃO INFANTIL: tensões evidenciadas}

Os dados da pesquisa evidenciam que as instituições pesquisadas originaram-se de movimentos filantrópicos - religiosa diocesana, centro espírita, maçonaria - tendo como objetivo atender às classes populares, liberar a mão de obra feminina e reproduzir uma educação ideológica às crianças, com preceitos morais que penetrem no seio familiar, além de gerar mais força de trabalho.

Chamou a atenção, durante a pesquisa, os padrões mínimos de infraestrutura para o funcionamento adequado das instituições de El. Do total das instituições pesquisadas $84,2 \%$ funcionam em condições precárias, com estruturas mínimas, como por exemplo, serviços básicos de água, esgoto sanitário, energia elétrica. Porém, outros elementos relacionados à infraestrutura e que atinge aspectos de saúde, inexistem em determinadas instituições, por exemplo, ausência de refrigeradores para manutenção de alimentos.

Há também ausência de área destinada à função de parque infantil. Somente em um dos municípios pesquisados há salas amplas e arejadas na instituição de El, banheiros em cada sala, adaptados à altura das crianças; espaço que possibilitava às crianças estarem ao ar livre. Em nenhuma instituição há disposição de bibliotecas; em contrapartida, a maioria dispunha de televisão e vídeo. Algumas instituições não possuem telefone fixo.

Diante desse quadro, afirma-se que ser trabalhadora em uma instituição de El na rede pública dos municípios pesquisados, significa frequentemente, atuar em estabelecimentos com pouco ou quase nenhum recurso. Por lei, essas condições deveriam ter sido cumpridas, a partir de cinco anos, após a aprovação do PNE.

A meta 4 do PNE determina que: "Adaptar os prédios de Educação Infantil de sorte que, em cinco anos, todos estejam conforme os padrões mínimos de infraestrutura estabelecidos" (BRASIL, 2001, p. 15). Os padrões mínimos referidos no plano deveriam ter sido definidos pelos órgãos competentes, como por exemplo, Conselho ou Secretaria de Educação de cada município, no prazo de um ano, após a publicação do PNE, ou seja, os dados da pesquisa evidenciam que os objetivos e metas ainda se encontram somente no papel para muitos usuários dessa etapa de educação, tanto as crianças quanto as trabalhadoras.

Entende-se que para que todos esses itens sejam cumpridos, é necessário que cada sistema crie a sua estrutura própria para normatizar, supervisionar e manter essas instituições de El, mas para isso, é preciso apoio financeiro e técnico.

A pesquisa evidenciou ainda a ausência de vagas para crianças dessa etapa de educação, por isso, a seleção se perpetua. Do total das instituições pesquisadas, somente em duas, as entrevistadas responderam que não havia nenhum critério de seleção e que, se houvesse vagas, toda e qualquer criança era matriculada. Na maioria das vezes, adota-se o seguinte critério: mães trabalhadoras domésticas - mensalistas ou diaristas -, e pais desempregados, visto que não é possível atender toda a demanda. Noutros espaços considera-se os seguintes critérios: ordem de 
chegada; "Declaração de Trabalho"5.

Verifica-se uma inversão de papeis. Ao invés de o pai, mãe ou responsável fazer cumprir a lei que determina o direito dessa criança frequentar a instituição, considerando a lei como um ordenamento jurídico de aplicação universal, que deve ser obedecida por todos os membros da sociedade, inclusive pelas instituições que a compõem, o que ocorre é o inverso. Pais e filhos são alijados de seus direitos adquiridos.

Ao analisar a sociedade capitalista, Marx (1983, p. 174) afirma que o trabalhador é um capital vivo, para sua infelicidade, o que fica evidente nessa afirmação: o trabalhador não existe enquanto homem, mas só enquanto trabalhador, quando há um capital para ele, ou seja, até o momento em que ele estiver produzindo bens e serviços, "a economia política não conhece o trabalhador desocupado". Ora, além de não considerar que a creche é um direito da criança, critérios evidenciados acima não levam em conta que a perda do emprego pelos pais ou responsáveis deveria ser um fato que contribuísse positivamente para uma vaga, e não como acontece, a negação do direito. Constatou-se que o trabalhador é formatado pelo capital das mais diferentes formas, utilizando a própria legislação, ao contrário do que é de direito.

Observam-se assim os traços dominantes da sociedade do capital, constituída com sua perspicaz destrutividade do ser humano, e, sobretudo, a fragilidade do trabalhador frente às difíceis condições vividas, utilizando-se de forma "legalizada" a exclusão de seus direitos. Como diria Marx (1983), o trabalhador, além de lutar pelos meios físicos de subsistência, deve lutar para alcançar trabalho. Completa-se: para que seus filhos não percam o que lhes é de direito - continuar na instituição de El.

Observou-se ainda que os ideais de família nuclear predominam nas instituições pesquisadas, por gênero, sendo que a mulher deve colocar no centro de sua vida o "cuidado" com os filhos e com o modelo idealizado de criança que parece ecoar de maneira muito forte. Percebe-se o apelo de diferentes trabalhadoras - diretoras, coordenadoras - para que se inspirem nos modelos de maternidade ao se relacionarem com as crianças. Segundo Carvalho (1999), essas questões se refletem nos corredores das escolas primárias brasileiras e aqui destaca-se as de El.

Algumas entrevistadas se expressaram em relação às atividades que elas desenvolvem afirmando que o objetivo da El é preparar a criança para entrar na escola regular ou porque os pais precisam de um lugar para deixar os filhos enquanto trabalham. Percebe-se que há uma preocupação em corroborar com duas funções exercidas no atendimento da El no Brasil: preparatória para o Ensino Fundamental e assistencialista.

Outro aspecto preocupante que se identificou na pesquisa é como os governantes conduzem as questões relativas à educação. Em relação à remuneração das trabalhadoras pesquisadas, a baixa remuneração impõe jornadas de trabalho exaustivas. Com o objetivo de alcançar uma remuneração minimamente digna, muitas trabalhadoras têm a jornada de trabalho nos três turnos (60 horas). As consequências são a perda de prestígio social da carreira do professor, interferindo na constituição da identidade política dessa trabalhadora.

Essa situação financeira das trabalhadoras remete a muitas contradições, das quais destaca-se duas, bastante latentes. A primeira, abordada por Carvalho (1999), ao pesquisar as diferentes dimensões do trabalho docente, diz respeito ao profissional que não podendo contar com recompensas salariais ou com desfrute de prestígio social, tem disposto de uma recompensa emocional, advinda dos vínculos afetivos que estabelece com as crianças. Percebe-se que, com

\footnotetext{
${ }^{5}$ A Declaração de Trabalho é um documento preenchido pelos pais e pelo empregador/empregadora, comprovando o trabalho realizado junto à empresa ou em residência. Caso o trabalhador consiga essa declaração há maior probabilidade da vaga ser assegurada.
} 
maior ou menor ênfase, essa observação se materializava nas instituições pesquisadas. Muitas educadoras articulavam a satisfação emocional aos aspectos cognitivos do trabalho docente, a satisfação de verem as crianças se desenvolverem.

A outra contradição é que, essa profissional que lutou para ser reconhecida e ter uma posição digna capaz de manter a sobrevivência, ao estender sua jornada de trabalho, vê-se ansiosa pela aposentadoria.

A pesquisa indica que, do total de trabalhadoras pesquisadas por município, em Chapadão do Céu $40 \%$ já tem idade para se aposentar, entretanto, nenhuma delas se referiu a vontade de se aposentar. Em Jataí $80 \%$ do total das entrevistadas afirmaram estar contando os dias para se aposentarem. Em Serranópolis 16,6\% das entrevistadas enfatizaram esse desejo. Essas aproximações e distanciamentos, em relação à necessidade de se aposentar conduz à reflexão sobre a não desvinculação do ser humano com o contexto onde ele vive.

Elementos da pesquisa evidenciam resistências das trabalhadoras nos fazeres diários, chamados na El de cuidados, muitas, aparentemente cansadas. O trabalho com a docência, especialmente com crianças menores, exige um grau de controle emocional muito grande, daí o esgotamento, o cansaço e o desgaste manifesto por muitas educadoras. Outros efeitos dessa exaustão apareciam nas faltas justificadas e licenças médicas de muitas profissionais. Essa questão também contraria a concepção fetichizada da imagem pública de professoras da El como um trabalho leve, fácil e pouco exigente, para o qual basta o amor.

Os dados da pesquisa evidenciou um elemento de aproximação nas sete instituições, mesmo com todas as dificuldades, $98 \%$ das 44 trabalhadoras pesquisadas, nas entrevistadas indicaram a profissão docente como uma vocação ${ }^{6}$, nesse sentido, essa vocação passa a ser condição essencial para o exercício da docência, o que implica uma atitude de resignação frente às dificuldades da profissão. Tem-se então a contradição da sociedade do capital, ou seja, ao mesmo tempo em que é proferido aos professores o discurso da abnegação, do amor, da naturalização da mulher para a docência, na verdade, também deprecia-se tudo que não tenha valor material.

Os elementos da pesquisa indicam que a ideia de feminização da docência pode ser compreendida, conforme afirma Carvalho (1999), como estabelecimento de características de gênero feminino para a ocupação de processos articulados. Ou seja, quanto mais a El é pensada como instância formadora de vontades, quanto menor forem às crianças atendidas, eximindo-a da transmissão de saberes, mais este trabalho se aproxima do trabalho com características femininas; de um docente "idealizado" e não "intelectualizado".

As repercussões desse tipo de proposição foram bastante visíveis na fala das trabalhadoras pesquisadas, especialmente a partir do conceito do amor, que precisa ter para atuar na El. Enfatizaram também o bom professor para esta etapa de educação como articulado a traços tipicamente femininos, como carinho, paciência e compreensão, atribuindo essas características ao instinto materno.

A boa educadora seria a "segunda mãe" para seus alunos. Muitas trabalhadoras classificaram as crianças como "carentes" e suas falas são marcadas, pelo discurso da doação, da vocação e do sacerdócio, destacando características como calma, amor, paciência, como parte fundamental de seus trabalhos. Ao analisar essas falas entende-se que as trabalhadoras, muitas vezes, recorriam a esses sentimentos por se encontrarem despreparadas teoricamente para ensinar crianças, principalmente às menores de três anos. Segundo Mello (1987), quando não se sabe o que se faz, ama-se.

\footnotetext{
${ }^{6}$ Em sua gênese a palavra vocação significa "chamado de Deus".
} 
Em suma, os dados da pesquisa evidenciam que o espontâneo, o lúdico, o prazer, o não-diretivismo, no trabalho pedagógico, foram os eixos de aproximação do trabalho das instituições pesquisadas. Essa identificação possibilitou a retomada da natureza da El e o questionamento feito inicialmente: o que então diferencia um clube, um parque, de uma instituição de El? Entende-se que a educação de crianças menores de 5(cinco) anos também se diferencia de outras etapas de educação escolar; entretanto, como afirma Arce (2005), deve ocorrer em ambientes institucionalizados - escola.

Como bem caracteriza Saviani, D. (2003, p. 14), quando aborda a concepção de ambiente institucional, "Portanto, a escola diz respeito ao conhecimento elaborado e não ao conhecimento espontâneo; ao saber sistematizado e não ao saber fragmentado; a cultura erudita e não a cultura popular". Para esse autor, a escola está focada na ciência que é um saber metódico e sistematizado; dessa forma, o ato de ensinar necessariamente deve ser dirigido e não escapa à transmissão ${ }^{7}$ do conhecimento.

Percebe-se, nas instituições pesquisadas, que há uma tendência de que a educação para crianças menores de cinco anos deve ser desvinculada do ensino e da aprendizagem (DANDOLINI; ARCE, 2009). Essa tendência legitima a "desintelectualização" docente e o trabalho da professora dessa etapa de educação passa a ser secundarizado, privilegiando a observação, a organização de espaços pedagógicos e o acompanhamento dos interesses da criança. Esse movimento na El tem relação com as críticas que ocorrem no campo educacional: ao recuo da teoria na pesquisa, ao esvaziamento do conteúdo na escola e à secundarização do conhecimento na formação dos professores.

Tendo como foco o trabalho docente na EI, é preciso superar o histórico pragmatismo. O cuidado e a educação de crianças nessa idade são importantes, porém, insuficientes para o pleno desenvolvimento dessas crianças e o efetivo exercício da docência dessas trabalhadoras. É preciso atentar para os modismos que se sucedem na área educacional, lucrativos para o mercado, entretanto, nocivos para as crianças e profissionais envolvidos.

Nesse sentido, entende-se a necessidade das trabalhadoras docentes da El se assumirem como professoras, ou seja, como profissionais do ensino. Assim, cabe a elas organizar intencionalmente e cientificamente o processo ensino-aprendizagem das crianças, fundamentado no que é relevante, levando em conta suas condições psicológicas, o que vai requerer formas adequadas de trabalho. Para Arce (2007), a natureza humana não está dada no ato do nascimento biológico e sim pelo trabalho educativo. Dessa forma, apropriar-se da cultura acumulada é um passo fundamental para a criança tornar-se humana, para seu nascimento como ser social, como ser humano. Saviani, D. (2003, p. 13) caracteriza o trabalho educativo como:

\footnotetext{
${ }^{7}$ Segundo Saviani, D. (2009) ensinar deriva do latino "insigno, avi, atum, insignare", que significa marcar com um sinal, imprimir, dar conhecer. Vê-se que o ensino deriva de signo, sinal. Santo Agostinho, na obra De magistro, escrita em 389 de nossa era, começa o diálogo com seu filho Deodato pela discussão do sentido e finalidade da linguagem, para mostrar em que consiste o ensino. Conclui-se que o homem só pode ensinar lançando mão de sinais, signos. Em nome de concepções renovadas estigmatizaram o ensino, vinculando-o com a Pedagogia Tradicional e aproximando o significado de inculcação de conteúdos mecânicos nas mentes dos alunos. Ainda para este autor, desde o surgimento da compreensão do conceito de ensino proposto pela Escola Nova, a sociedade tendeu a condenar o processo de transmissão de conhecimento, com a alegação que ao transmitir saber os professores limitavam a liberdade e criatividade do aluno, afirmação errônea em seu cerne, pois a transmissão de saberes sistematizados é condição libertadora do gênero humano, uma vez que o aluno só alcança a liberdade quando for plenamente ensinado, quando internalizar os conhecimentos e dominá-los (SAVIANI, D., 2003).
} 


\begin{abstract}
[...] ato de produzir direta e intencionalmente, em cada indivíduo singular, a humanidade que é produzida histórica e coletivamente pelo conjunto dos homens. Assim, o objeto da educação diz respeito, de um lado, a identificação dos elementos culturais que precisam ser assimilados pelos indivíduos da espécie humana para que eles se tornem humanos e, de outro lado concomitantemente, à descoberta das formas mais adequadas para atingir esse objetivo.
\end{abstract}

Esse discurso distancia do apreendido na pesquisa, o ensino ganha status de protagonista nesse novo cenário, mesmo entendendo que a educação não se reduz a isso e que, na El o processo de ensinar se diferencia dos outros níveis de educação, pois a criança menor de cinco anos tem suas peculiaridades; porém, não se pode abrir mão do saber sistematizado.

A apropriação efetiva do sujeito, em relação aos processos e fenômenos do mundo objetivo ocorre por meio das relações com os outros homens, ou seja, por meio da educação. Como afirma Arce; Baldan (2009, p. 189, grifo do autor):

\begin{abstract}
A apropriação da cultura constitui o que é 'ser homem' na sociedade em que nasceu, marcando assim o nascimento social. A criança, ao nascer, apresenta-se apenas como um membro da espécie animal humana, que, aos poucos, com o trabalho de transmissão da cultura humana realizado pelos adultos que a rodeiam, vai transformando-se em um membro do gênero humano, da humanidade.
\end{abstract}

Dessa forma, o cuidar não é o simples ato de limpar, higienizar, alimentar e colocar para dormir. Considera-se essas demandas de trabalho necessárias, mas complementares à formação humana na infância, pois juntas contribuem para a constituição do humano no corpo da criança, o professor irá promover o nascimento da criança para o mundo social. Essas características demandarão mudanças no trabalho do professor, um profissional cuja prática deve vincular-se aos estudos e ao planejamento, um trabalho intencional de apresentação do mundo para a criança desde a mais tenra idade.

\title{
5 | CONSIDERAÇÕES FINAIS
}

A pesquisa, que deu origem a esse artigo, teve como referência a opção teórico-metodológica marxiana, buscando, por meio dele, compreender o trabalho como elemento constitutivo para a humanidade.

Para que o trabalho realizado com crianças menores de cinco anos atenda, de fato, o direito de todas as crianças a uma educação de qualidade, que pretenda ser efetivamente humanizada, promotora do máximo de desenvolvimento da criança, é preciso direcionar as ações na contramão da concepção que naturaliza a infância.

Para isso, faz-se necessário compreender a El no processo histórico e social de formação de seres humanos e dessa forma, a trabalhadora que atua nessas instituições deve ser aquela que promova o desenvolvimento e aprendizagem da criança, pois entende-se que esse profissional juntamente com outros adultos que povoam a vida da criança são os responsáveis para a completude de seu nascimento biológico e de sua inserção no mundo social.

Percebeu-se, durante todo o processo da pesquisa evidências de concepções de ideários que fetichizavam a existência das crianças pequenas, interferindo no trabalho realizado pelas trabalhadoras dessa etapa de educação, o que pouco ou nada tem contribuído para a consolidação de ações educativas nessas instituições. Defende-se os espaços das instituições de El como 
lócus de um trabalho pedagógico sistematicamente ancorado no domínio da ciência, independente da idade daqueles que atendem.

Evidências indicam que em determinadas situações as práticas fetichizadas do trabalho educativo continuam com o modelo assistencialista, as crianças ficam soltas, livres e a instituição acaba tornando mais um espaço de lazer e de ocupação do tempo do que um espaço propriamente destinado ao ensino. Essa problemática contribui para a constituição de outra: a secundarização do trabalho da professora, visto que, se o ensino e a aprendizagem estão desvinculados da El e a criança é acompanhada conforme seu interesse, qual seria então a função da trabalhadora nessa etapa de educação?

Faz-se necessário (des) naturalizarmos o processo de aprendizagem na El e o papel da professora nela inserida, pois, a professora dessa etapa de educação deve ser aquela que supera a improvisação, saiba ensinar, tenha rigor filosófico e disciplina metodológica, criatividade e criticidade na forma de entender e trabalhar o conhecimento. Por isso a formação da trabalhadora da EI não pode se eximir de uma bagagem sociológica, antropológica, filosófica, histórica, social e política, além de uma séria abordagem didático-metodológica, capaz de teorizar sobre a educação e sua relação com a sociedade, a partir do que possa refletir sobre sua prática e ter perspectivas de mudanças significativas na educação e na sociedade. Ou seja, deve ser ciente de que seu papel pedagógico é o início do processo criador, um trabalho de formação imprescindível do ser humano.

Na realidade pesquisada identificou-se essa complexidade. Porém, Marx (1983) já salientava que para a compreensão da realidade é necessário esforço para, partindo dos fatos observados que são as aparências dadas pela realidade, superá-las para chegar à essência. O que aproxima e distancia as realidades são as contradições e a ideologização da realidade. O pensamento ideologizado não é um pensamento equivocado, é aquele que apanha os elementos da realidade tal qual ela se encontra, não apreendendo seus nexos constitutivos. Assim sendo, acaba naturalizando aquilo que é histórico e social, como se bastasse ser mãe e gostar de crianças para ser professora de crianças pequenas. 


\section{Referências}

ALVARENGA, V. C. A carreira das professoras de educação infantil: indícios de precarização e intensificação do trabalho. In: ARCE, A.; JACOMELI, M. R. M. (Org.). Educação infantil versus educação escolar?: entre a (des)escolarização e a precarização do trabalho pedagógico nas salas de aula. Campinas: Autores Associados, 2012. p. 151-174.

ARCE, Alessandra. Compre o kit neoliberal para a educação infantil e ganhe grátis os dez passos para se tornar um professor reflexivo. Educação e Sociedade, ano XXII, n 74, Abril/2001. p. 251-283

ARCE, A. A formação de professores sob a ótica construtivista: primeiras aproximações e alguns questionamentos. In: DUARTE, N. Sobre o construtivismo. São Paulo: Autores Associados, 2005. p. 41-62.

O referencial curricular nacional para a educação infantil e o espontaneísmo. In: ARCE, A.; MARTINS, L. M. Quem tem medo de ensinar na educação infantil?: em defesa do ato de ensinar. Campinas: Alínea, 2007.p. 13-36.

Pedagogia da infância ou fetichismo da infância? In: DUARTE, N. (Org.). Crítica ao fetichismo da individualidade. Campinas: Autores Associados, 2004. p. 145-168.

ARCE, A.; BALDAN, M. A criança menor de três anos produz cultura?: criação e reprodução em debate na apropriação da cultura por crianças pequenas. In: ARCE, A.; MARTINS, L. M. Ensinando aos pequenos: de zero a três anos. Campinas: Alínea, 2009. p. 187-204.

BRASIL. Lei $n^{\circ} 11.274$, de 6 de fevereiro de 2006. Altera a redação dos arts. 29, 30, 32 e 87 da Lei no 9.394, de 20 de dezembro de 1996, que estabelece as diretrizes e bases da educação nacional, dispondo sobre a duração de 9 (nove) anos para o ensino fundamental, com matrícula obrigatória a partir dos 6 (seis) anos de idade. Diário Oficial da União. Brasília, DF, 7 fev. 2006.

BRASIL, Ministério da Educação e Cultura. Lei $n^{\circ}$ 10.172, de 9 de janeiro de 2001. Aprova o Plano Nacional de Educação e dá outras providências. Câmara dos Deputados. Brasília, DF: Editora Plano, 2001. p. 1-184.

CAMPOS, M. M.; CRUZ, S. H. V. Consulta sobre qualidade da educação infantil: o que pensam e querem os sujeitos deste direito. São Paulo: Cortez, 2006.

CARVALHO, M. P de. No coração da sala de aula: gênero e trabalho docente nas séries iniciais. São Paulo: Xamã, 1999.
DANDOLINI, M. R.; ARCE, A. A formação de professores de educação infantil: algumas questões para se pensar a profissional que atuará com crianças de 0 a 3 anos. In: ARCE, A.; MARTINS, L. M. Ensinando aos pequenos: de zero a três anos. Campinas: Alínea, 2009. p. 51-92.

FAZENDA, I. (Org.). Metodologia da pesquisa educacional. São Paulo: Cortez, 1989.

FREITAS, L. C. Crítica da organização do trabalho pedagógico e da didática. Campinas: Papirus, 1995.

FRIGOTTO, G. O enfoque da dialética materialista histórica na pesquisa educacional. In: FAZENDA, I. (Org.). Metodologia da pesquisa educacional. São Paulo: Cortez, 1989. p. 69-90.

HADDAD, L. A creche em busca de identidade. São Paulo: Loyola, 1993.

KISHIMOTO, T. M. Política de formação profissional para a educação infantil: pedagogia e normal superior. Educação e Sociedade, Campinas, v. 20, n. 68, p. 61-79, 1999.

KRAMER, S. A política do pré-escolar no Brasil: a arte do disfarce. São Paulo: Cortez, 2003.

KUHLMANN JUNIOR, M. Educação infantil e currículo. In: FARIA, A. L. G.; PALHARES, M. S. (Org.). Educação infantil pós-LDB: rumos e desafios. São Paulo: Autores Associados, 1999. p. 51-65.

. Infância e educação infantil: uma abordagem histórica. Porto Alegre: Mediação, 1998.

KUHLMANN JUNIOR, M.; FERNANDES, R. Sobre a história da infância. In: FARIA FILHO, L. M. (Org.). A infância e sua educação: materiais, práticas e representações. Belo Horizonte: Autêntica, 2004. p. 15-33.

LAKATOS, E. M.; MARCONI, M. de A. Fundamentos de metodologia científica. São Paulo: Atlas, 1986.

LUCKESI, C. C. Avaliação da aprendizagem escolar. São Paulo: Cortez, 1995.

LUKÁCS, G. Ontologia do ser social: os princípios ontológicos fundamentais de Marx. São Paulo: Livraria Editora Ciências Humanas, 1979.

MARTINS, L. M.; ARCE, A. A educação infantil e o ensino fundamental de nove anos. In: (Org.). Quem tem medo de ensinar na educação infantil?: em defesa do ato de ensinar. Campinas-SP: Alínea, 2007, p. 37-62 
.MARX, K. O capital: crítica da economia política. São Paulo: Nova Cultural, 1983.

MELLO, G. N. de. Magistério primeiro grau: da competência técnica ao compromisso político. São Paulo, Cortez, 1987.

MERISSE, A. Origem das instituições de atendimento à criança pequena: o caso das creches. In: . Lugares da infância: reflexões sobre a história da criança na fábrica, creche e orfanato. São Paulo: Arte \& Ciência, 1997.

MÉSZÁROS, I. Para além do capital: rumo a uma teoria da transição. São Paulo: Boitempo, 2002.

PARO, V. H. Gestão democrática da escola pública. São Paulo: Ática, 2000.

PRADO, A. E. F. G.; AZEVEDO, H. H. O. Currículo para educação infantil: argumentos acadêmicos e propostas de "educação" para crianças de 0 a 5 anos. In: ARCE, A.; JACOMELI, M. R. M. (Org.). Educação infantil versus educação escolar?: entre a (des)escolarização e a precarização do trabalho pedagógico nas salas de aula. Campinas: Autores Associados, 2012. p. 33-52.

ROSEMBERG, F. Organizações multilaterais, estado e políticas de educação infantil. Cadernos de Pesquisa, São Paulo, n. 115, p. 25-63, mar. 2002. Disponível em: <http://www.google.com.br/search>. Acesso em: 23 ago. 2009.

SANTOS FILHO, J. C. dos; GAMBOA, S. S. (Org.). Pesquisa educacional: quantidade e qualidade. São Paulo: Cortez, 2001.
SAVIANI, D. Ensino público: algumas falas sobre universidade. São Paulo: Cortez, 1991.

. O trabalho como princípio educativo frente as novas tecnologias. 1994. p. 1-15. Disponível em: <http:// www.ufpr.cleveron.com.br/arquivos/EP_104/dermeval_ saviani.pdf>. Acesso em: 23 fev. 2015.

Pedagogia histórico-crítica: primeiras aproximações. Campinas: Autores Associados, 2003.

Prefácio. In: ARCE, A.; MARTINS, L. M. (Org.). Ensinando aos pequenos: de zero a três anos. Campinas: Alínea, 2009. p. 7-13.

SAVIANI, N. Educação infantil versus educação escolar: implicações curriculares de uma (falsa) oposição. In: ARCE, A.; JACOMELI, M. R. M. (Org.). Educação infantil versus educação escolar?: entre a (des)escolarização e a precarização do trabalho pedagógico nas salas de aula. Campinas: Autores Associados, 2012. p. 53-80.

STEMMER, M. R. G. Educação infantil e alfabetização. In: ARCE, A.; MARTINS, L. M. Quem tem medo de ensinar na educação infantil?: em defesa do ato de ensinar. Campinas: Alínea, 2007. p. 125-146.

Educação infantil: gênese e perspectivas. In: ARCE, A.; JACOMELI, M. R. M. (Org.). Educação infantil versus educação escolar?: entre a (des)escolarização e a precarização do trabalho pedagógico nas salas de aula. Campinas: Autores Associados, 2012. p. 5-32. 